\title{
Using Cmap Cloud in the cooperative development of interactive concept maps to improve academic performance
}

\section{Concept maps, cooperative work and academic performance.}

Ignasi Navarro Soria, Carlota González Gómez, Fernando López Becerra, Francisco Fernández Carrasco,

\author{
Jorge Heliz Llopis \\ Universidad de Alicante, Spain \\ ignasi.navarro@ua.es, carlota.gonzalez@ua.es, f.lopez@ua.es, \\ francisco.fernandez@ua.es, jorge.heliz@ua.es
}

\begin{abstract}
For this study, 148 students were recruited, and they consisted of two experimental groups and one control group. Both experimental groups were instructed in the development of conceptual maps using the CmapTools software, while the students in the control group freely chose which study strategies they would use to acquire the knowledge that would be evaluated. The difference between the two experimental groups was that one of the experimental groups followed the guidelines of a cooperative activity, developing a conceptual map in work teams (4 students to each team) usingCmapCloud, while in the other experimental group, each student developed the contents of a conceptual map in CmapTools on an individual level. The objective was to detect whether there would be any statistically significant differences between the three groups at the level of academic performance. For this purpose, the same sample was tested by means of the same type of knowledge acquisition test. The data obtained reveal that the scores are higher in the experimental groups than in the control group, and in turn, the experimental group that included cooperative work obtained a better level of performance than the experimental group that worked at the individual level. Therefore, we conclude that simple modifications in the pedagogical strategy (introducing an effective learning strategy and cooperative work), would significantly improve the teaching-learning process and, consequently, would significantly improve the average performance of the students.
\end{abstract}

Keywords - conceptual map, academic performance, meaningful learning, cooperative learning, Cmap Cloud

Subject Classification: Pedagogic strategy

Type (Method/Approach):Research in Educational Methods/ Quasi-experimental applied research

Supporting Agencies: Instituto de Ciencias de la Educación (ICE)

\section{Introduction}

A student can present multiple learning styles, as well as a diversity of tools for the acquisition of knowledge, adjusting these to their capacities and qualities as an apprentice and to the content of the knowledge base to be acquired. In the body of scientific literature that deals with this subject, throughout the development of the related research, special attention has been paid to learning styles and knowledge acquisition tools that have a better relationship with effectiveness or academic performance [1] [2] [3] [4] [5] [6] [7] [8]. The results of these investigations have shown that the information acquired by the significant learning model presents a greater resistance to the passing of time and gives the individual a greater capacity to solve new problems [9] [10] [11]. 
This discourse, which promulgates the need to stimulate in our students a significant and lasting learning experience, has gained strength during recent decades. Along with it, changes are being made in the processes of instruction, changes that imply the active involvement of the student in the development of knowledge, interaction with peers in the classroom and the consolidation of vicarious learning processes as a vehicle for the acquisition of knowledge and skills.

Today's society, which may be very different in twenty years time, demands committed professionals who 1) benefit from the different perspectives that their colleagues can offer, 2) learn from shared experiences, and 3) are capable of developing critical, constructive and productive thinking that adapts to the highly variable needs of the existing work environments, in order to solve common problems that are encountered bythe work team.

The fact of working cooperatively to achieve a common goal is not a new concept because it is part of the social character of the human being. The learning approach that emanates from the cooperation of a group of studentsresponds to a greater innovation, not only regarding theoretical content, but also with respect to relational skills. Our society and the current world of work, are mainly characterized and sustained by the processes of creation, management and dissemination of information. Further, isolated worker who develops his task without any interconnection with his environment and who does not need a team to achieve objectives of a certain size and difficulty is becoming increasingly less effective. In opposition to the prototype of the self-sufficient student and the self-sufficient professional, a more social and interdependent perspective of each of the members of a society, organization or group is building a momentum, with a vision that requires participants from different areas to collaborate with others in order in order to face common goals and challenges [12].

In line with this perception of academic work and job-based work, the individuals of our society must show adequate competences for meaningful/critical learning and cooperative work, and it is fundamental that the future graduates in the educational institutions are instructed to learn and work in this sense.

Among the learning strategies, which are repeatedly cited as being more effective with respect to acquiring meaningful learning, the conceptual map, and specifically the interactive conceptual map,has prominence [13] [14] [15] [16]. This type of learning helps the incorporation of new knowledge into the cognitive structure of the individual, thanks to the basic processes of assimilation and accommodation. The information acquired through this strategy presents a greater resistance to the passing of time. At the same time, the correct elaboration of a conceptual map has a positive effect on the attitudes and levels of satisfaction of the students with respect to their academic results [6] [16]. In fact, in previous research results [8] [11] [17] [18], a statistically positive relationship has been established between the use of study techniques, cooperative learning, and academic performance.

\section{Materials and Methods}

\section{Description of the context and the participants}

The experiment was undertaken with a sample of 148 university students of the Faculty of Education of the University of Alicante, Alicante, Spain during the implementation of the subject: DevelopmentalPsychology for the Primary Education Teacher. This discipline is taught during the first semester in the first year of a Teaching degree program, therefore, for most of the students it is their first contact with the University.

\section{Instrument / Educational innovation}

There is a multitude of tools for developing a conceptual map, but in order to elaborate an interactive conceptual map in a cooperative way, an information and communication technologies (ICT) tool is required that allows the modification, enrichment and development of the content according to the best of our knowledgein the subject under study. In the present study, the CmapTools program was chosen. The 
CmapTools program was developed by the Florida Institute for Human and Machine Cognition (IHMC) and more specifically regarding its web-based version:CmapCloud. Among the services offered, we highlight:1)clarifying and organizing information, 2)facilitating study, 3)promoting critical thinking, 4)identifying key concepts, and 5)promoting creativity. In view of the aforementioned characteristics, it is noteworthy that one of the services offered by the web-based version is the synchronous modification of the same conceptual map, thus facilitating cooperative work. The important aspect is not so much the final result that is obtained, but the process of elaboration of the conceptual map. In relation to this, we find the option to review the process, that is carried out in a step-by-step manner, to be beneficial both for the individual student orfor a group of students in the construction process, and for the subsequent evaluation by the tutor.

Process

The procedure carried out for the research has consisted of, from 3 groups / classroom of students, different learning strategies have been assigned to the experimental group 1 formed by 54 students (individual elaboration of interactive conceptual maps), to the experimental group 2 formed by 46 student (elaboration of interactive conceptual map through cooperative work) and the control group formed by 48 students. All assiduously attend master classes that are taught by the same tutor. The contents treated during the development of the discipline, are worked through different strategies as they belong to the control group or to the experimental groups. The experimental group 1 carries out its study by developing interactive conceptual maps at the individual level using the CmapTools tool, the experimental group 2 carries out its study by developing interactive conceptual maps through cooperative work using the CmapCloud tool, while the control group works at the level individual using the learning strategies that each of them considers relevant. To assess the learning outcomes, the same test type is used to which the total sample of participants is faced. The questions of the test type test require to apply the understanding of the contents, since they are interrogated by means of brief practical cases.

\section{Results and Discussion}

The results show that the distribution of students according to the final grade obtained in the subject is favorable for both Experimental Group 1 and Experimental Group 2, and for the control group. As can be seen in Table 1, if we group the students who obtain a grade of notable and outstanding, in Experimental Group $2,84.8 \%$ of students meet the requirement. In turn, following this same premise for Experimental Group 1, $68.6 \%$ of students meet the requirement, while in the control group $50 \%$ of students achieve a similar grade.

Table 1. Distribution of students according to the grade obtained in the exam type of test

\begin{tabular}{llcccccc} 
& & \multicolumn{2}{c}{$\begin{array}{c}\text { Experimental } \\
\text { Group 1 }\end{array}$} & $\begin{array}{c}\text { Experimental } \\
\text { Group 2 }\end{array}$ & \multicolumn{2}{c}{$\begin{array}{c}\text { Control } \\
\text { Group }\end{array}$} \\
\cline { 3 - 8 } & & $\mathrm{n}$ & $\%$ & $\mathrm{n}$ & $\%$ & $\mathrm{n}$ & $\%$ \\
& Excellent & 9 & 16.7 & 12 & 26.1 & 3 & 6.3 \\
Assessment frequency & Notable & 28 & 51.9 & 27 & 58.7 & 21 & 43.7 \\
$\left(\boldsymbol{X}^{\mathbf{2}=\mathbf{5 . 4 5}} \boldsymbol{p}=\mathbf{0 . 0 1}\right)$ & Sufficient & 12 & 22.2 & 5 & 10.9 & 17 & 35.4 \\
& Insufficient & 5 & 9.2 & 2 & 4.3 & 7 & 14.6 \\
\hline
\end{tabular}

On the other hand, when taking into account the results obtained in the analysis of the differences between sample means, it is reasonable to expect that the more complete the pedagogy strategy used during content instruction, the more that strategywill positively influence the probability of obtaining a better grade in the 
exam using theoretical evaluation. Therefore, the logistic regression analyses have been carried out in order to examine the influence of the different pedagogical strategies on a better assessment and evaluation of the student, by means of final test type test, the results show that the proportion of cases correctly classified by the logistic models (see Table 2$)$ was $91.3 \%\left(\chi^{2}=71.73, p=0.00\right)$ for experimental group 1 , of $89.2 \%\left(\chi^{2}=\right.$ $32.13, p=0.00)$ for experimental group 2 and $89.4 \%\left(\chi^{2}=46.82 ; p=0.00\right)$ for the control group.

The Nagelkerke $\mathrm{R}^{2}$ statistic has oscillated in the estimation of the adjustment value between 0.12 for Experimental Group 1 and 0.25 for Experimental Group 2.

Based on the values of the Odds Ratio (OR) (see Table 2), the probability that students will improve their performance in the subject of Developmental Psychology, increases by $23 \%$ if they have previously developed interactive conceptual maps for their study, $42 \%$ if they have previously developed interactive conceptual maps for their study through a cooperative learning strategy, and $9 \%$ if they freely chose a study strategy at their own discretion.

Table 2. Logistic regression for the predictive probability that, the higher the qualification after the evaluation of theoretical contents, the greater the probability of a more complex use of instructional strategies

$\begin{array}{lllllllll}\text { Variable } & \chi^{2} & R^{2} & B & \text { E.T. } & \text { Wald } & p & \text { OR } & \text { C.I. } 95 \%\end{array}$

$\begin{array}{llllllllll}\begin{array}{c}\text { Experimental } \\ \text { Group 1 }\end{array} & \text { Correct } \\ & \text { classification: 89.2\% } & 32.13 & .12 & 0.20 & 0.03 & 28.58 & .00 & 1.23 & 1.14-1.32\end{array}$

$\begin{array}{llllll}\text { Constant } & 0.08 & 0.36 & 0.05 & .81 & 1.08\end{array}$

\begin{tabular}{|c|c|c|c|c|c|c|c|c|c|}
\hline \multirow{3}{*}{$\begin{array}{l}\text { Experimental } \\
\text { Group } 2\end{array}$} & \multicolumn{9}{|l|}{ Correct } \\
\hline & classification: $91.3 \%$ & 71.73 & 0.25 & 0.35 & 0.04 & 57.86 & .00 & 1.42 & $1.29-1.55$ \\
\hline & Constant & & & -2.11 & 0.56 & 17.48 & .00 & 0.12 & \\
\hline \multirow[t]{3}{*}{ Control Group } & Correct & & & & & & & & $1.06-1.12$ \\
\hline & classification: $89.4 \%$ & 46.92 & .18 & 0.09 & 0.01 & 38.77 & .00 & 1.09 & \\
\hline & Constant & & & -0.74 & 0.42 & 2,97 & .08 & 0.47 & \\
\hline
\end{tabular}

\section{Conclusions}

Previous research [18] [19] undertook studies with characteristics that are very similar to those in the present study, since in both of them an experimental group of university students was evaluated, which made use of CmapTools with respect to a control group of individuals who used other methods of study of their own free choosing. The results of the present study are analogous with the results of the two aforementioned investigations from the body of literature, since they found that the highest percentage of grades, around notable or outstanding, was obtained by the experimental group. 
In this case, the experimental group is divided into two sub-groups, according to the practice of conceptual mapping,which is carried out through either a cooperative work activity or an individual level activity. If the conceptual map is developed by a work team, then the CmapCloud version is used, which allows a synchronous development of the contents among different students and which also gives rise to the joint development of a cooperative learning. Our data confirm that the performance at the level of the acquisition of academic knowledge was significantly higher when the students used Cmap Cloud than when students usesCmapTools as a study tool, but they did so on an individual basis. On the other hand, the control group freely chose which study strategies they wished to use, based on their previous experiences and learning styles. Although the results are good in relation to those obtained by Experimental Group 1 and Experimental Group 2, they are significantly low.

Based on these results, it can be categorically stated that the use of pedagogical techniques that advocate meaningful learning, whereby students manipulate knowledge and develop that knowledge, and where the tutor implements a guiding role through learning, there is a significant improvement in the quality of learning by the student while improving the direct results of the exam grades.

Conflicts of Interest

The authors declare that there are no conflicts of interest.

Funding Statement

The present work is part of the REDES-I3CE Program of research in university teaching of the Educational Sciences of the University of Alicante (call 2017-18), Ref.:[4098]

\section{References}

[1] Acevedo Pierart, C. \& Rocha Pavés, F. (2011).Learning styles, gender and academic performance. RevistaEstilos de Aprendizaje, 8(8), 1-16.

[2] Cid, F. M., Acevedo, V. B., \& Garrido, C. A. (2016). Relationship between the learning styles and the academic performance of physical education students of the S.E.K. University of Chile. RevistaCiencias de la ActividadFísica, 16(2).

[3] Gallardo, B., Almerich, G., Suárez, J., García, E., Pérez, C., \& Fernández, A. (2013). Learning approaches of excellent university students and their means. Their evolution throughout the first career year.RevistaBordón, 65(2), 75-96.

[4] López, J. M. B., \&Velásquez, F. R. (2013).Learning styles and locus of control in students who enter higher education and their link with academic performance. Investigación y Postgrado, 23(3), 199-215.

[5] Luengo-Cervera, E. (2015). Learning styles and multiple intelligences in the teaching-learning of spanish as a foreign language. Enseñanza\&Teaching, 33(2), 79-103.

[6] Montero, E., Sepúlveda, M., \& Contreras, E. (2011).Cross-sectional study of learning styles and academic performance in the first year of a career in Veterinary Medicine. Revista de Estilos de Aprendizaje,7(7), 151159.

[7] Serra-Olivares, J., Valverde, C. L. M., Armero, C. C., \& Madrona, P. G. (2017).Learning styles and academic performance of Chilean university students undertaking Physical Education studies.Retos, 32, 62-67.

[8] Navarro-Soria, I., González-Gómez, C., Galipienso, A., Contreras, A., López-Becerra, F., Fernández-Carrasco, F. \&Heliz, J. (2014). Use of studytechniques and academic success in undergraduate students at the University of Alicante, Spain.IN: M. Tortosa, J. Álvarez and N. Pellín, XII Jornadas de Redes de Investigación en Docencia Universitaria (pp. 2494-2509). Universidad de Alicante, Alicante, Spain.

[9] Moreira, M. A. (2012). In the end, what exactly is meaningful learning? Qurriculum: revista de teoría, investigación y práctica educativa. 25, 29-56. 
[10] Novak, J. D., \& Cañas, A. J. (2006). Thetheoryunderlying conceptual maps and how to build them. Florida Institute for Humanand Machine Cognition(IHMC), Florida, USA. Retrieved from:http://cmap.ihmc.us/Publications/researchPapers/teoriaCmaps/teoriasubyacentemapasconceptuales -ORIG.html

[11] Navarro-Soria, I., González-Gómez, C., López-Becerra, F., Fernández-Carrasco, F. \&Heliz, J. (2016).The interactive conceptual map as a reflexive tool in favor of construction of meaningful learning.IN: $M$. Tortosa, S. Grau and J. Álvarez, XIV Jornadas de Investigación en Docencia Universitaria (págs. 2017-2027). Universidad de Alicante,Alicante, Spain.

[12] Badia, A. (2005). Learning to collaborate with the Internet in the classroom.IN:Monereo, C. (coord.), Internet and basic skills. Learning to collaborate, communicate, participate, and learn.Graó,Barcelona, Spain.

[13] Cañas, A. J., Ford, K. M., Coffey, J., Reichherzer, T., Carff, R., Shamma, D., Hill, G., Suri, N. \& Bready, M. (2000). Tools with which to build and share knowledge models based on conceptual maps. Revista De InformáticaEducativa, 13(2), 145-158.

[14] Costamagna, A. (2001). Conceptual maps as an expression of interrelation processes in order to evaluate the evolution of knowledge in university students.Enseñanza de la Ciencias, 19(2), 309-318.

[15] Novak, J. D., \&Musonda, D. (1991). A twelve-year longitudinal study of science concept learning. American Educational Research Journal, 28(1), 117-153. http://dx.doi.org/10.3102/00028312028001117.

[16] Rossi, L., Lopetegui, M., \&Doná, S. (2010). Strategies of learning and academic performance according to gender in university students.Revista de Psicología, 11, 199-211.

[17] Navarro-Soria, González-Gómez, C. \&Botella, P. (2015). Project-basedlearning: perceiveddifferences in the acquisition of competences by the university student. Revista de Psicología y Educación, 10(1), 55-76.

[18] Navarro-Soria, I., Real, M. \& González-Gómez, C. (2017). CmapTools as a key for improving academic achievement in University students. International Journal of Modern Education Research, 4(6) , 81-84.

[19] Murga-Menoyo, M. A., Bautista-Cerro, M. J., \& Novo, M. (2011). Conceptual mapswithCmapTools in theuniversityeducationprogram of Environmental Education. A case study in the National University of Distance Learning (UNED), Spain. Enseñanza de las ciencias, 29(1), 47-59. 